\title{
Oxygen consumption in platelets as an adjunct diagnostic method for pediatric mitochondrial disease
}

Emil Westerlund ${ }^{1}$, Sigurður E. Marelsson ${ }^{1}$, Johannes K. Ehinger ${ }^{1}$, Fredrik Sjövall ${ }^{1}$, Saori Morota ${ }^{1}$, Eleonor Åsander Frostner ${ }^{1}$, Anders Oldfors ${ }^{2}$, Niklas Darin ${ }^{3}$, Johan Lundgren ${ }^{4}$, Magnus J. Hansson ${ }^{1}$, Vineta Fellman ${ }^{4}$ and Eskil Elmér ${ }^{1}$

BACKGROUND: Diagnosing mitochondrial disease (MD) is a challenge. In addition to genetic analyses, clinical practice is to perform invasive procedures such as muscle biopsy for biochemical and histochemical analyses. Blood cell respirometry is rapid and noninvasive. Our aim was to explore its possible role in diagnosing MD.

METHODS: Blood samples were collected from 113 pediatric patients, for whom MD was a differential diagnosis. A respiratory analysis model based on ratios (independent of mitochondrial specific content) was derived from a group of healthy controls and tested on the patients. The diagnostic accuracy of platelet respirometry was evaluated against routine diagnostic investigation.

RESULTS: MD prevalence in the cohort was 16\%. A ratio based on the respiratory response to adenosine diphosphate in the presence of complex I substrates had $96 \%$ specificity for disease and a positive likelihood ratio of 5.3. None of the individual ratios had sensitivity above $50 \%$, but a combined model had $72 \%$ sensitivity.

CONCLUSION: Normal findings of platelet respirometry are not able to rule out MD, but pathological results make the diagnosis more likely and could strengthen the clinical decision to perform further invasive analyses. Our results encourage further study into the role of blood respirometry as an adjunct diagnostic tool for MD.

$F$ or the clinician facing a severely sick child with indistinct but serious symptoms such as seizures, hypotonia, or liver failure, mitochondrial disease (MD) is one of the conditions that need to be considered.

While certain diagnoses have a characteristic clinical picture, and some cases can be rapidly confirmed by targeted genetic testing, diagnosing MD is often a challenge $(1,2)$.

Standardized clinical criteria have been proposed to facilitate a general mitochondrial diagnosis and rely on a combination of symptoms and tests of varying difficulty $(3,4)$. Elevated blood lactate is an important indicator for MD, but is nonspecific and may be caused by numerous systemic conditions such as hypoxia or sepsis (5). Cerebrospinal fluid lactate is more specific in diagnosing mitochondrial encephalopathy, but requires an invasive procedure (6). Magnetic resonance imaging of the brain may show typical patterns (as in Leigh syndrome) or less specific pathology. Analysis of organic acids in urine, like lactate, is noninvasive but may have low sensitivity if the patient is clinically stable (7).

A muscle biopsy is often necessary to confirm the diagnosis. It is used for biochemical, histochemical, and, in some cases, genetic analyses $(1,8,9)$. Muscle biopsy is an invasive procedure requiring sedation or most often general anesthesia in children. Fresh muscle tissue is preferred over frozen and patients need to be transferred to centers with accredited laboratories for such analyses (7). Physicians can obviously not order this investigation on too wide a suspicion, nor expect expeditious results. While new methods of genetic testing facilitate large nuclear gene panels and whole-exome sequencing, and will likely play an increasingly important role in the future, they are not considered first-line diagnostic tools.

An accessible mitochondrial test derived from a normal blood sample would be of value to direct the early stages of diagnostic investigations. Mitochondrial function in platelets

Table 1. Demographic profile of patients and controls

\begin{tabular}{lcc}
\hline & Patients $(n=113)$ & Controls $(n=25)$ \\
\hline Median age in years (IQR) & $3(0.5-9.5)$ & $3(1-7)$ \\
Under 1 month & & \\
1 month to 1 year & $24(21)$ & $0(0)$ \\
$1-5$ years & $30(27)$ & $2(8)$ \\
$5-15$ years & $40(35)$ & $12(48)$ \\
15 years or older & $7(6)$ & $11(44)$
\end{tabular}

Female/male, $n(\%) \quad 62(55) / 51(45) \quad 7(28) / 18(72)$

Abbreviation: IQR, interquartile range.

\footnotetext{
${ }^{1}$ Mitochondrial Medicine, Department of Clinical Sciences, Lund University, Lund, Sweden; ${ }^{2}$ Department of Pathology, Institute of Biomedicine, University of Gothenburg, Gothenburg, Sweden; ${ }^{3}$ Department of Pediatrics, The Queen Silvia Children's Hospital, University of Gothenburg, Gothenburg, Sweden; ${ }^{4}$ Department of Pediatrics, Skåne University Hospital, Lund University, Lund, Sweden. Correspondence: E Westerlund.

(emil.westerlund@med.lu.se)

Received 3 May 2017; accepted 19 September 2017; advance online publication 15 November 2017. doi:10.1038/pr.2017.250
} 


\section{Articles | Westerlund et al.}

Table 2. Symptoms and findings

\begin{tabular}{|c|c|c|c|}
\hline \multicolumn{2}{|l|}{ Clinical data } & \multicolumn{2}{|c|}{ Test results } \\
\hline Symptom or finding & $n$ & Type of test & $\begin{array}{c}\text { Pathologic }(n) \text { : } \\
\text { normal }(n)\end{array}$ \\
\hline Total patients reported & 113 & Metabolic tests & \\
\hline Birth complications & 5 & P-lactate & 39:56 \\
\hline CNS & & $\begin{array}{l}\text { Organic acids in } \\
\text { urine }\end{array}$ & $9: 6$ \\
\hline Intellectual disability & 46 & $\begin{array}{l}\text { Organic acids in } \\
\text { blood }\end{array}$ & $1: 0$ \\
\hline Seizures & 40 & $\begin{array}{c}\text { Amino acids in } \\
\text { urine }\end{array}$ & $1: 8$ \\
\hline $\begin{array}{l}\text { Hypotonia/muscle } \\
\text { weakness }\end{array}$ & 35 & $\begin{array}{l}\text { Amino acids in } \\
\text { blood }\end{array}$ & $0: 7$ \\
\hline Psychomotor regression & 31 & $\begin{array}{l}\text { Triglyceride or } \\
\text { carnitine }\end{array}$ & $4: 3$ \\
\hline Ataxia & 8 & CSF & \\
\hline Episodic vomiting & 8 & Lactate & $10: 6$ \\
\hline Pain/polyneuropathy & 8 & Protein & 7:5 \\
\hline Dystonia & 5 & Pyruvate & $2: 4$ \\
\hline Headache/migraine & 5 & $\begin{array}{l}\text { Lactate/pyruvate } \\
\text { ratio }\end{array}$ & $2: 1$ \\
\hline Nystagmus & 5 & Imaging studies & \\
\hline Spasticity & 5 & MRI or CT findings & $24: 13$ \\
\hline Apnea & 4 & $\begin{array}{c}\text { Other clinical } \\
\text { physiology studies }\end{array}$ & \\
\hline Hypoventilation & 2 & EEG & $14: 4$ \\
\hline Microcephaly & 2 & & \\
\hline Stroke & 2 & ECG & $5: 5$ \\
\hline Hypertonia & 1 & UCG & $4: 6$ \\
\hline Other CNS symptoms & 6 & NCS & $3: 1$ \\
\hline Skeletal muscle and heart & & EMG & $1: 0$ \\
\hline Cardiomyopathy & 8 & & \\
\hline Hypotension & 3 & & \\
\hline Myopathy & 3 & & \\
\hline Hypertension & 2 & & \\
\hline Other cardiac symptoms & 4 & & \\
\hline \multicolumn{4}{|c|}{ Ophthalmologic symptoms and findings } \\
\hline Ptosis & 5 & & \\
\hline Visual loss & 5 & & \\
\hline External ophtalmoplegia & 3 & & \\
\hline Optic nerve atrophy & 2 & & \\
\hline Retinitis pigmentosa & 1 & & \\
\hline $\begin{array}{l}\text { Other ophtalmologic } \\
\text { symptoms }\end{array}$ & 3 & & \\
\hline \multicolumn{4}{|c|}{ Gastrointestinal symptoms and findings } \\
\hline Vomiting & 14 & & \\
\hline Dysphagia & 3 & & \\
\hline Other Gl symptoms & 3 & & \\
\hline
\end{tabular}

Endocrine symptoms and findings

Growth retardation
Table 2. Continued

\begin{tabular}{|c|c|c|c|}
\hline \multicolumn{2}{|l|}{ Clinical data } & \multicolumn{2}{|c|}{ Test results } \\
\hline Symptom or finding & $n$ & Type of test & $\begin{array}{l}\text { Pathologic }(n) \text { : } \\
\text { normal }(n)\end{array}$ \\
\hline Diabetes mellitus & 1 & & \\
\hline $\begin{array}{l}\text { Other endocrine } \\
\text { symptoms and findings }\end{array}$ & 1 & & \\
\hline \multicolumn{4}{|l|}{ Other symptoms and features } \\
\hline $\begin{array}{l}\text { Liver symptoms and } \\
\text { findings }\end{array}$ & 10 & & \\
\hline Dysmorphism & 5 & & \\
\hline Hearing loss & 5 & & \\
\hline Scoliosis & 3 & & \\
\hline $\begin{array}{l}\text { Airway symptoms and } \\
\text { findings }\end{array}$ & 2 & & \\
\hline $\begin{array}{l}\text { Renal symptoms and } \\
\text { findings }\end{array}$ & 2 & & \\
\hline Anemia & 1 & & \\
\hline Fever & 1 & & \\
\hline $\begin{array}{l}\text { Psychiatric symptoms } \\
\text { and findings }\end{array}$ & 1 & & \\
\hline $\begin{array}{l}\text { Abbreviations: CNS, central nerv } \\
\text { tomography; ECG, electrocardio } \\
\text { myography; Gl, gastrointestinal; } \\
\text { duction studies; UCG, echocardi }\end{array}$ & sys & $\begin{array}{l}\text { CSF, cerebrosp } \\
\text { electroenceph } \\
\text { ic resonance }\end{array}$ & $\begin{array}{l}\text { luid; } C T \text {, computed } \\
\text { ahy; EMG, electro- } \\
\text { g; NCS, nerve con- }\end{array}$ \\
\hline
\end{tabular}

has been suggested as a marker of systemic mitochondrial function and has been studied in a variety of conditions where mitochondrial dysfunction is part of the pathology, such as amyotrophic lateral sclerosis, Alzheimer's disease, and sepsis (10-12).

Only a few studies have investigated blood cells from patients with primary MD, mostly in lymphocytes. Results have indicated that blood cell mitochondria are affected in some primary MDs, but study populations have often been small (13-16). Two studies on lymphocyte respirometry suggest candidate measurements for diagnostic use $(14,16)$.

To our knowledge, no published study has evaluated respirometry in blood cells as a diagnostic method on a larger group of patients where MD was a differential diagnosis.

The aim of this study was to investigate the value of platelet respirometry as a complement to existing diagnostic tests for MD. The method is rapid and noninvasive and could be performed in the early stages of investigation.

\section{RESULTS}

\section{Clinical data}

The study included 113 patients where MD was considered a differential diagnosis. A wide pediatric age span was represented in the material, but most patients were under 5 years (Table 1). Central nervous system symptoms were heavily featured among reported symptoms (Table 2). 
Table 3. Cases with confirmed mitochondrial disease

\begin{tabular}{|c|c|c|c|c|c|}
\hline \multirow{2}{*}{\multicolumn{2}{|c|}{ Mitochondrial disease }} & \multirow{3}{*}{$\begin{array}{l}\text { Main clinical findings } \\
\text { Ophthalmoparesis, central deafness, congenital heart } \\
\text { defect }\end{array}$} & \multicolumn{2}{|c|}{ Genetic findings } & \multirow{3}{*}{$\begin{array}{l}\text { Main supportive diagnostic findings for } \\
\text { patients without known genetic defect }\end{array}$} \\
\hline & & & \multirow{2}{*}{$\begin{array}{l}\text { Gene } \\
\text { MT-ND5 }\end{array}$} & \multirow{2}{*}{$\begin{array}{l}\text { Mutation }^{\mathrm{a}} \\
\text { m.13513G >A }\end{array}$} & \\
\hline 1 & Leigh syndrome & & & & \\
\hline 2 & MELAS & Myopathy, cardiomyopathy, stroke & MT-TL1 & $\mathrm{m} .3260 \mathrm{~A}>\mathrm{G}$ & \\
\hline 3 & Alpers syndrome & $\begin{array}{l}\text { Intellectual disability, epilepsy, hypotonia, } \\
\text { cardiomyopathy }\end{array}$ & POLG & NA & \\
\hline 4 & PDH deficiency & $\begin{array}{l}\text { Hypotonia, delayed psychomotor development, } \\
\text { microcephaly }\end{array}$ & PDHA1 & c.1142_1145 dupATCA & \\
\hline 5 & $\begin{array}{l}\text { Mitochondrial } \\
\text { encephalopathy }\end{array}$ & Hypotonia, cardiomyopathy, hepatopathy & - & - & $\begin{array}{l}\text { Elevated plasma lactate, increased lactate on } \\
\text { MR spectroscopy, COX-negative fibers in } \\
\text { muscle biopsy }\end{array}$ \\
\hline 6 & PDH deficiency & Psychomotor regression, microcephaly, hypotonia & PDHA1 & c. $871 \mathrm{G}>\mathrm{A}$ & \\
\hline 7 & $\begin{array}{l}\text { Alpers-Huttenlocher } \\
\text { syndrome }\end{array}$ & $\begin{array}{l}\text { Hypotonia, psychomotor regression, liver failure, } \\
\text { epilepsy, adrenal insufficiency }\end{array}$ & POLG & $\begin{array}{l}\text { p.W748S, p.Q497H, p. } \\
\text { R852C, p.E1143G }\end{array}$ & \\
\hline 8 & $\begin{array}{l}\text { Mitochondrial } \\
\text { encephalopathy }\end{array}$ & $\begin{array}{l}\text { Visual loss, cardiomyopathy, pancreas insufficiency, } \\
\text { apnea, hypotonia, polyneuropathy }\end{array}$ & - & - & $10-20 \%$ COX-negative fibers in muscle biopsy \\
\hline 9 & CPEO and myopathy & External ophtalmoplegia, ptosis, muscle weekness & MT-TN & $\mathrm{m} .5703 \mathrm{G}>\mathrm{A}$ & \\
\hline 10 & $\begin{array}{l}\text { Mitochondrial } \\
\text { depletion syndrome }\end{array}$ & Liver failure, polyneuropathy, dystonia & MPV17 & c. $191 C>G, c .503 A>G$ & \\
\hline 11 & $\begin{array}{l}\text { Mitochondrial } \\
\text { hepatopathy }\end{array}$ & $\begin{array}{l}\text { Respiratory failure, progressive hypotonia, } \\
\text { hepatopathy, cholestasis }\end{array}$ & - & - & $\begin{array}{l}\text { Elevated plasma and CSF lactate, decreased } \\
\text { amount of complexes I, III and IV in BNGE of } \\
\text { isolated liver mitochondria }\end{array}$ \\
\hline 12 & $\begin{array}{l}\text { Kearns-Sayre } \\
\text { syndrome }\end{array}$ & External ophtalmoplegia, retinitis pigmentosa, ptosis & - & - & $\begin{array}{l}\text { Elevated CSF protein, 5-10 \% COX-negative } \\
\text { fibers and RRF in muscle biopsy, large mtDNA } \\
\text { deletion of probable pathogenicity }\end{array}$ \\
\hline 13 & LHON plus & $\begin{array}{l}\text { Vision loss, psychomotor regression, hypotonia, } \\
\text { epilepsy }\end{array}$ & MT-ND4 & $\mathrm{m} .11778 \mathrm{G}>\mathrm{A}$ & \\
\hline 14 & Leigh syndrome & $\begin{array}{l}\text { Psychomotor regression, progressive hemiparesis, } \\
\text { dystonia, respiratory failure }\end{array}$ & - & - & $\begin{array}{l}\text { Elevated CSF lactate and bilateral basal ganglia } \\
\text { lesions on MRI }\end{array}$ \\
\hline 15 & PDH deficiency & $\begin{array}{l}\text { Intellectual disability, hypotonia, microcephaly, } \\
\text { epilepsy, cyclic vomiting }\end{array}$ & PDHA1 & $\begin{array}{l}\text { c.1068- } \\
\text { 1078deITCCTGAGCCAC }\end{array}$ & \\
\hline 16 & Leigh syndrome $^{\mathrm{b}}$ & Ataxia, spasticity, psychomotor regression & SLC19A3 & $\mathrm{C} 153 \mathrm{~A}>\mathrm{G}, \mathrm{c} .157 \mathrm{~A}>\mathrm{G}$ & \\
\hline 17 & $\begin{array}{l}\text { Mitochondrial } \\
\text { depletion syndrome }\end{array}$ & $\begin{array}{l}\text { Psychomotor regression, bilateral sensorineural hearing } \\
\text { loss, dyskinesia }\end{array}$ & SUCLA-2 & c. $751 \mathrm{G}>\mathrm{A}$ & \\
\hline 18 & $\begin{array}{l}\text { Mitochondrial } \\
\text { encephalopathy }\end{array}$ & $\begin{array}{l}\text { Epilepsy, hypotonia, lactic acidosis, pulmonary } \\
\text { hypertension }\end{array}$ & SARS2 & c. $691 \mathrm{C}>\mathrm{G}, \mathrm{c} .868 \mathrm{C}>\mathrm{T}$ & \\
\hline
\end{tabular}

Abbreviations: BNGE, Blue Native gel electrophoresis; COX, cytochrome oxidase; CPEO, chronic progressive external ophthalmoplegia; CSF, cerebrospinal fluid; HUPRA, hypertension, renal failure, and alkalosis; LHON, Leber's hereditary optic neuropathy; MELAS, mitochondrial encephalomyopathy, lactic acidosis, and stroke-like episode; MRI, magnetic resonance imaging; mtDNA, mitochondrial DNA; NA, not available; PDH, pyruvate dehydrogenase; RRF, ragged red fibers.

Case numbers correspond to Table 6.

${ }^{a}$ At least one of listed mutations assessed to be pathogenic.

${ }^{\text {b} T h i a m i n e ~ t r a n s p o r t e r-2 ~ d e f i c i e n c y . ~}$

'Suspected HUPRA syndrome. 


\section{Articles | Westerlund et al.}

Thirty-three patients went through a more extensive clinical investigation including muscle biopsy, genetic testing, or both. Eighteen patients were confirmed to have MD and the basis for these diagnoses is presented in Table 3. Five patients still had suspected but unconfirmed MD after extended investigation. These patients were considered as not having MD for all calculations in the study. In the remaining 90 cases, routine clinical investigation did not indicate MD (Figure 1).

\section{Evaluation of diagnostic respiratory ratios}

Absolute values for platelet respirometry in the reference group and established reference bounds for respiratory ratios are shown in Table 4. Diagnostic evaluation of the six separate tests (4 one-sided ratios and 1 two-sided ratio) and the combined model is presented in Table 5. Oxidative

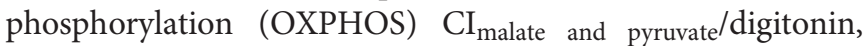
malate and pyruvate successfully identified 4 out of $18 \mathrm{MD}$ patients, with few false positives resulting in $96 \%$ specificity and a positive-likelihood ratio (PLR) of 5.3. Low values of Log (ETS $\mathrm{CI}+\mathrm{II} /$ Routine) and $\triangle \mathrm{ADP}$ (adenosine diphosphate)/ $\Delta$ Succinate identified 9 and $6 \mathrm{MD}$ patients, respectively. The remaining two tests had no true positives. The sensitivity for the combined model (positive here being defined as testing positive in any of the six tests) was $72 \%$ and the specificity $56 \%$. No single test had higher sensitivity than $50 \%$.

Table 6 shows an overview of the 18 MD patients' individual respirometry results in relation to other clinical tests. Thirteen out of the $18 \mathrm{MD}$ patients were identified by at least one respiratory ratio.

\section{Explorative analyses}

A correlation between high blood lactate and pathologic respirometry results has previously been described (14). We plotted respiratory ratios in relation to lactate values (Figure 2), and while no linear correlation was seen, selected tests in combination with high lactate improved specificity
(Table 7). A low OXPHOS $\mathrm{CI}_{\mathrm{MP}} / \mathrm{DMP}$ ratio in combination with high lactate had $99 \%$ specificity and a PLR of 21 . Also, $\log (\mathrm{ETS} \mathrm{CI}+\mathrm{II} /$ Routine $)$ and $\Delta \mathrm{ADP} / \Delta$ Succinate, respectively, combined with high lactate raised specificity and PLR.

Positive result in all of the three best tests had 100\% specificity for MD, but this model only identified three of the patients. A scaled down version of the main model, using only the two most sensitive tests and counting a positive result on either test or on both tests as positive, retained a sensitivity of $67 \%$ and raised specificity to $73 \%$ (Table 7 ). Finally, when applying stricter criteria for true positive, defining confirmed diagnosis as confirmed by genetic testing, sensitivity and specificity for the three best tests and the combined model did not change conspicuously (Table 8).

\section{DISCUSSION}

We show that platelet respirometry provides useful diagnostic information through a rapid and noninvasive procedure in pediatric patients, in whom MD was clinically considered a differential diagnosis. Positive results substantially increase the likelihood of MD.

Diagnosis of $\mathrm{MD}$ is a clinical challenge. $\mathrm{MD}$ is the most common group of inherited metabolic disorders, but their diverse presentation and complex pathophysiology make them hard to investigate. Many of the patients are young children with severe symptoms and the invasiveness or inaccessibility of the best diagnostic methods may delay or even prevent confirmation of diagnosis.

The study population is a representative cohort of pediatric patients with clinically suspected MD at a tertiary hospital, making the study highly relevant to clinicians investigating these often severely sick children. The prevalence of MD in the study population was $16 \%$, in line with previous reports from patient cohorts with similar clinical presentation $(6,14,23)$.

Oxygen consumption in platelets was assessed to evaluate mitochondrial function. We used ratios rather than absolute

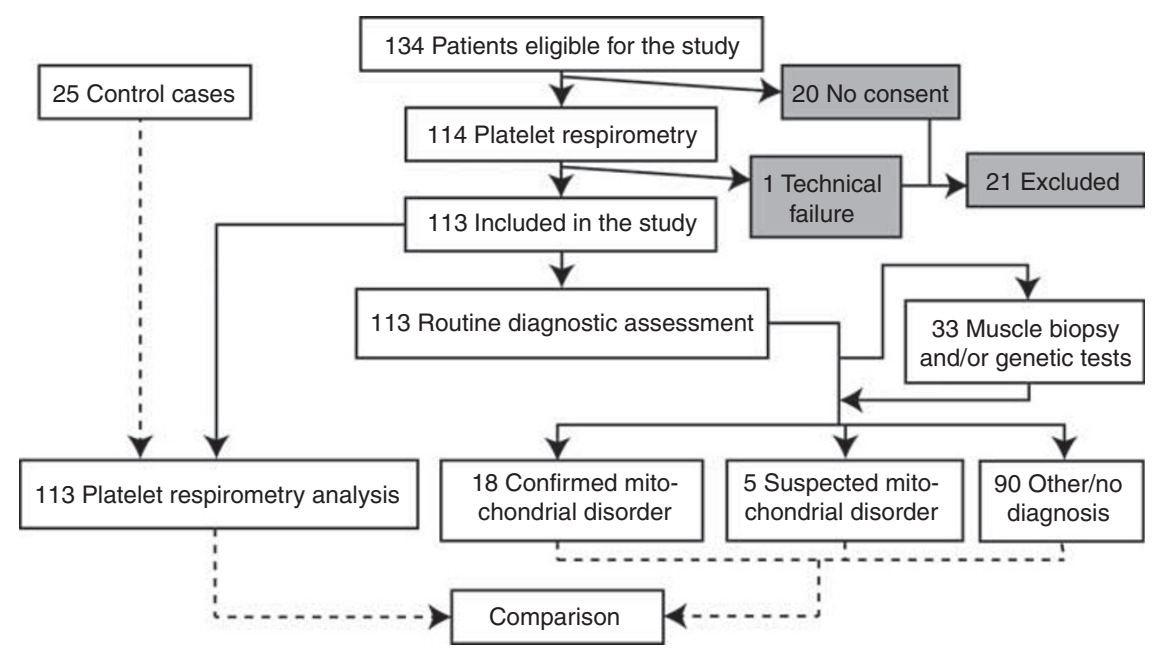

Figure 1. Study design. Two additional patients with technical failure were reanalyzed and the cases included. 
values of oxygen consumption, circumventing the need to calculate and adjust for mitochondrial content in the samples. A low OXPHOS $\mathrm{CI}_{\mathrm{MP}} / \mathrm{DMP}$ ratio had high specificity (96\%) and a PLR of 5.3, meaning that in this sample the likelihood of disease rose from 16 to $50 \%$ after testing positive. The ratio was constructed to be sensitive to CI dysfunction, as inadequate response to ADP in the presence of $\mathrm{CI}$ substrates would lower the ratio $(14,16)$. While all true-positive findings had confirmed CI dysfunction according to the current standard investigation, some patients with CI dysfunction were not caught by the test.

The ratio OXPHOS $\mathrm{CI}_{\mathrm{MP}} / \mathrm{DMP}$ had a low sensitivity, possibly only detecting severe dysfunction. $\log (\mathrm{ETS} \mathrm{CI}+\mathrm{II} /$ Routine) and $\Delta \mathrm{ADP} / \Delta$ Succinate appear to better detect mild dysfunction; they were more sensitive and their true positives overlap those of OXPHOS $\mathrm{CI}_{\mathrm{MP}} / \mathrm{DMP}$. Pathological results in all three best tests made the diagnosis of mitochondrial disorder very likely (in this material 100\% specificity). Each ratio was chosen to test a different aspect of the ETS (electron transport system) and thus a relatively low sensitivity for MD of any kind is expected when looking at the ratios individually. The combined model had a higher sensitivity at $72 \%$ but suffered from many false positives.

Although not enough to rule out disease on its own (negative likelihood ratio (NLR) of 0.5), platelet respirometry may be a useful part of an investigation. With the currently used diagnostic procedures, each individual test is in most cases insufficient to rule out MD, and that is also the case with this method. Blood respirometry has the advantage of swiftness, low invasiveness, and potential high availability and could be performed early in an investigation. In this material, two patients with normal muscle biopsy that later were confirmed to have MD by genetic testing had pathologic respirometry.

Plasma lactate is known to be a sensitive indicator of MD and can be obtained easily. A combination of high lactate and a low OXPHOS $\mathrm{CI}_{\mathrm{MP}} / \mathrm{DMP}$ ratio had $99 \%$ specificity (Table 7), comparable to the highest estimates of cerebrospinal fluid lactate, which is a markedly more invasive method (6). The likelihood for disease in a patient testing positive rose from 16 to $80 \%$. Cerebrospinal fluid lactate is primarily suitable to detect MD affecting the central nervous system and has lower specificity in acutely ill patients $(24,25)$. Blood lactate values, in contrast to platelet respirometry results, were technically not independent from the clinical findings that informed the final diagnosis. However, elevated lactate did not have a pivotal role for any of the MD diagnoses (Table 3).

We hypothesized that a limitation of OXPHOS at complex $\mathrm{V}(\mathrm{CV})$ would yield higher ETS than OXPHOS and result in a low OXPHOS CI+II/ETS CI+II ratio, indicating CV dysfunction. No patient had biochemically or genetically confirmed dysfunction in $\mathrm{CV}$, so this hypothesis could not be tested.

A low OXPHOS $\mathrm{CI}_{\mathrm{MP}} / \mathrm{OXPHOS} \mathrm{CI}_{\mathrm{MPG}}$ ratio failed to single out any of the three patients with pyruvate dehydrogenase (PDH) deficiency, despite them being identified by other ratios. 


\section{Articles | Westerlund et al.}

Table 5. Diagnostic evaluation of the main model

\begin{tabular}{|c|c|c|c|c|c|c|c|c|}
\hline Test $(n=113)$ & $\begin{array}{l}\text { Confirmed } \\
\text { MD }(n=18)\end{array}$ & $\begin{array}{l}\text { No confirmed } \\
\text { MD }(n=95)\end{array}$ & $\begin{array}{c}\text { Sensitivity } \\
(95 \% \mathrm{Cl})\end{array}$ & $\begin{array}{l}\text { Specificity } \\
(95 \% \mathrm{Cl})\end{array}$ & $\begin{array}{c}\text { PPV } \\
(95 \% \mathrm{CI})\end{array}$ & $\begin{array}{c}\text { NPV } \\
(95 \% \mathrm{Cl})\end{array}$ & $\begin{array}{c}\text { PLR } \\
(95 \% \mathrm{CI})\end{array}$ & $\begin{array}{c}\text { NLR } \\
(95 \% \mathrm{Cl})\end{array}$ \\
\hline \multicolumn{9}{|l|}{ OXPHOS $C I_{M P} / D M P$ low } \\
\hline Positive (8) & 4 & 4 & $22(6-48)$ & 96 (90-99) & $50(16-84)$ & 87 (79-93) & $5.3(1.5-19)$ & $0.81(0.63-1.04)$ \\
\hline Negative (105) & 14 & 91 & & & & & & \\
\hline \multicolumn{9}{|l|}{ Log(ETS Cl+II/Routine) low } \\
\hline Positive (27) & 9 & 18 & $50(26-74)$ & $81(72-88)$ & $33(17-54)$ & $90(81-95)$ & $2.6(1.4-4.9)$ & $0.62(0.38-0.99)$ \\
\hline Negative (86) & 9 & 77 & & & & & & \\
\hline \multicolumn{9}{|l|}{ OXPHOS Cl+II/ETS Cl+ll low } \\
\hline Positive (1) & 0 & 1 & 0 & $99(94-100)$ & 0 & $84(76-90)$ & 0 & $1.01(0.99-1.03)$ \\
\hline Negative (112) & 18 & 94 & & & & & & \\
\hline \multicolumn{9}{|l|}{$\triangle A D P / \triangle$ Succinate low } \\
\hline Positive (17) & 6 & 11 & $33(13-59)$ & $88(80-94)$ & $35(14-62)$ & 88 (79-93) & $2.9(1.2-6.8)$ & $0.75(0.54-1.05)$ \\
\hline Negative (96) & 12 & 84 & & & & & & \\
\hline \multicolumn{9}{|l|}{$\triangle A D P / \triangle$ Succinate high } \\
\hline Positive (21) & 2 & 19 & $11(1-34)$ & $80(71-88)$ & $9.5(1.2-30)$ & $83(73-90)$ & $0.56(0.14-2.2)$ & $1.1(0.92-1.4)$ \\
\hline Negative (92) & 16 & 76 & & & & & & \\
\hline \multicolumn{9}{|c|}{ OXPHOS $C I_{M P} / O X P H O S C I_{M P G}$ low } \\
\hline Positive (4) & 0 & 4 & 0 & $96(90-99)$ & 0 & $83(75-90)$ & 0 & $1.0(1.0-1.1)$ \\
\hline Negative (109) & 18 & 91 & & & & & & \\
\hline \multicolumn{9}{|l|}{ Combined model (6 tests) } \\
\hline Any test positive (55) & 13 & 42 & $72(47-90)$ & $56(45-66)$ & $24(13-37)$ & $91(81-97)$ & $1.6(1.1-2.4)$ & $0.50(0.23-1.07)$ \\
\hline All tests negative (58) & 5 & 53 & & & & & & \\
\hline
\end{tabular}

Abbreviations: ADP, adenosine diphosphate; DMP, digitonin, malate and pyruvate; $95 \% \mathrm{Cl}, 95 \%$ confidence interval; Cl+Il, complex I and Il; ETS, electron transport system; MD, mitochondrial disease; MP, malate and pyruvate; MPG, malate, pyruvate and glutamate; OXPHOS, oxidative phosphorylation; PLR, positive likelihood ratio; NLR, negative likelihood ratio; PPV, positive predictive value; NPV, negative predictive value.

Disease prevalence in the study population was $16 \%$.

Study limitations include insufficient information on any ongoing, potentially confounding medical treatment at the time of sampling (14). Further, the diversity of MD makes categorizing at all levels problematic. Although a clinical definition of confirmed MD was thought to best serve the aims of this study, a strict biochemical or genetic definition may have facilitated more detailed comparisons. (A strict genetic definition of true positive would arguably have had the benefit of less ambiguity. We included a post hoc analysis with such a definition, in which the main findings largely remains the same.) Also, the number of MD patients in the study was limited and many of the subdiagnoses were only represented by one patient each. The results therefore need to be confirmed by further studies. Another reason such studies are warranted is that the circumstances of data collection and analysis in this pilot project did not allow for strict blinding, something that would have to be readdressed in a follow-up investigation.

Lastly, the inherent problem of tests with significant falsenegative rates needs to be taken into account (if future models do not improve sensitivity), making sure a negative result in platelet testing alone does not unintentionally refrain the diagnostician from pursuing further investigations when needed. We do not expect blood cell respirometry to replace any part of the current diagnostic workup, but believe that the addition of this rapid test could potentially reduce time to diagnosis for certain patients.

When discussing the possible role of blood respirometry, it is important to consider not just the current clinical practices but also how they are projected to evolve. As mentioned above, genetic methods such as next-generation sequencing, either in the form of large-scale gene panels, whole-exome 


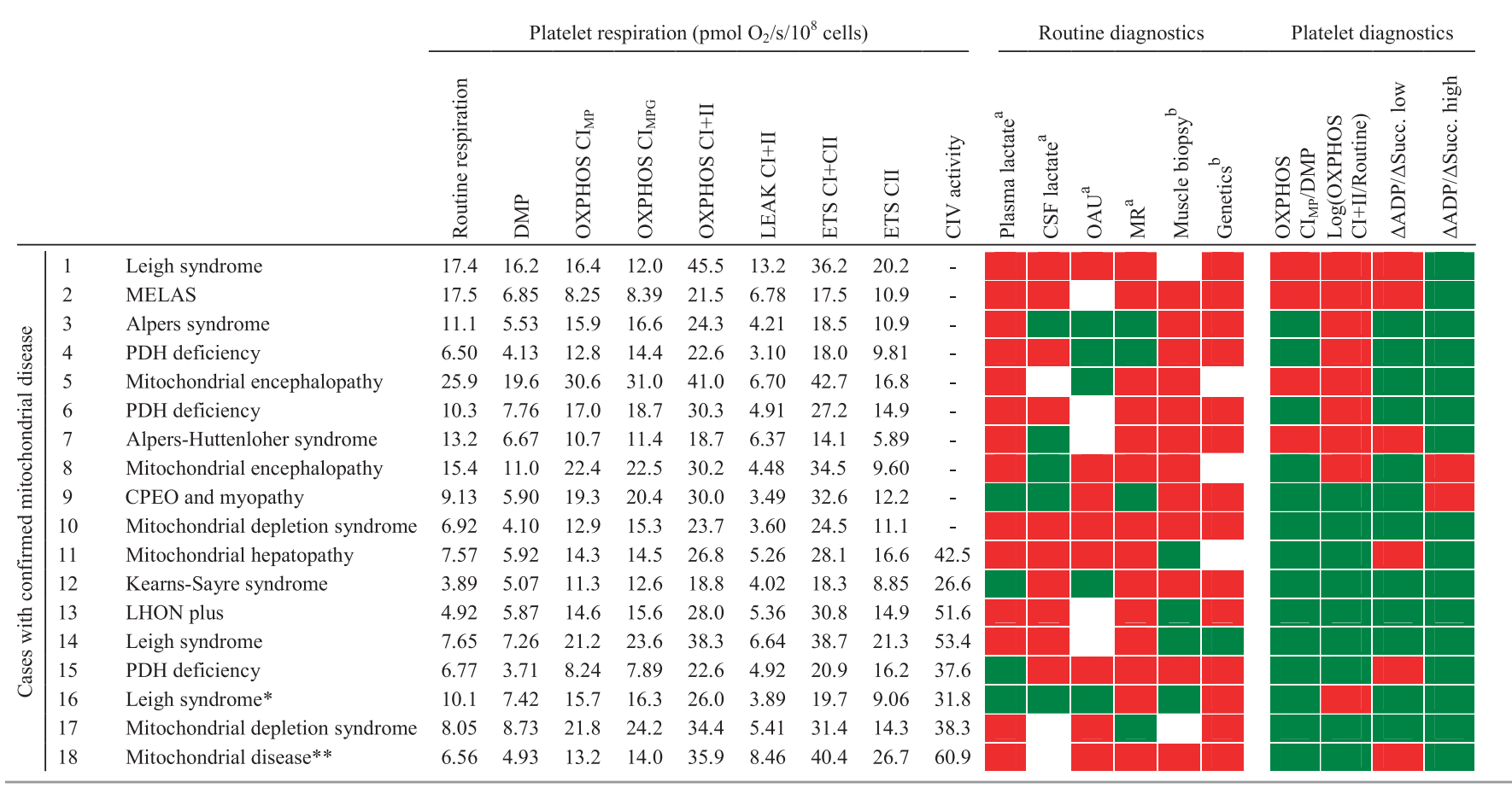

Abbreviations: ADP, adenosine diphosphate; Cl, complex l; CPEO, chronic progressive external ophthalmoplegia; CSF, cerebrospinal fluid; DMP, digitonin, malate and pyruvate; ETS, electron transport system; HUPRA, hypertension, renal failure, and alkalosis; LHON, Leber's hereditary optic neuropathy; MD, mitochondrial disease; MELAS, Mitochondrial encephalomyopathy, lactic acidosis, and stroke-like episode; MP, malate and pyruvate; MPG, malate, pyruvate and glutamate; MR, magnetic resonance; OXPHOS, oxidative phosphorylation; PDH, pyruvate dehydrogenase.

(a) green, normal result; red, any pathologic result. (b) green, result not indicating MD; red, pathologic result indicating MD.

*Thiamine transporter-2 deficiency.

**Suspected HUPRA syndrome on genetic basis.

sequencing or in some settings whole-genome sequencing, are currently gaining traction $(2,26)$. Interestingly, as one recent review pointed out, improved genetic testing may actually place greater emphasis on less invasive tests and methods to confirm pathogenicity (26). Blood cell respirometry may potentially be a part of the first-line screening arsenal, and as such it would not likely be replaced by large-scale genetic testing any time soon. Additionally, respirometry being a functional analysis, we see it as a complement rather than a competitor to genetic tests.

\section{CONCLUSION}

We have shown that pathologic platelet respirometry, as defined in this study, increased the likelihood of MD in a clinically relevant situation. Combining blood respirometry with blood lactate further increased its diagnostic yield. As it is a fast method with low invasiveness and potentially high availability, these results encourage further study into the method's possible role as an adjunct diagnostic tool for MD.

\section{METHODS}

\section{Patients and control subjects}

Patient samples were collected at the Skåne University Hospital (Lund, Sweden). Patients under the age of 18 years presenting from July 2008 through December 2013, where MD was clinically considered as a differential diagnosis by the attending physician, were eligible for the study. Patients with malignant disease were excluded. The pediatric control group comprised samples from patients undergoing anesthesia for minor elective surgery (inguinal hernia repair or phimosis surgery). Control group samples were drawn before induction of anesthesia. Written informed consent was obtained from parents or guardians. The regional ethical review board of Lund, Sweden, approved this study (59/2009 and 97/2009). All patients were given standard care and the study was conducted according to the Declaration of Helsinki.

\section{Clinical data and routine diagnostic assessment}

The standard care of patients included in the trial was not affected by the results of this study, as no patient was excluded from further clinical investigation based on a negative blood cell respirometry. Clinical data were reported by clinicians and supplemented with review of medical records in Lund and at Sahlgrenska University Hospital, Gothenburg (where a majority of the muscle biopsies and genetic analyses were performed). Muscle biopsies were analyzed according to established practices (including histology, spectrophotometry, and oximetry/respirometry, normally all three) $(7,8)$. Genetic analyses included screening for suspected mutations with or without the addition of whole-exome sequencing.

Patients were considered to have confirmed disease when a specialist in pediatric neurology had documented the diagnosis of MD as confirmed in the patient journal, after compiling the results of the investigation.

This definition was, as with the inclusion criteria, chosen to most closely adhere to the clinical reality. Although in practice the Bernier criteria are generally used at the participating hospitals in this study, there are neither national nor regional guidelines for diagnosing MD. A suspected case of MD not disproven during early investigation (due to, for instance, confirmation of an alternative diagnosis or 


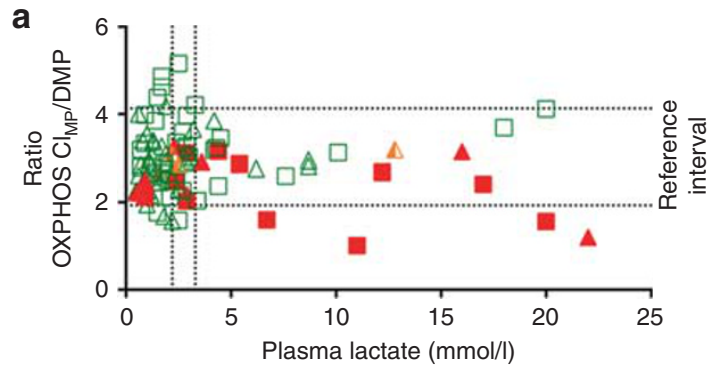

b
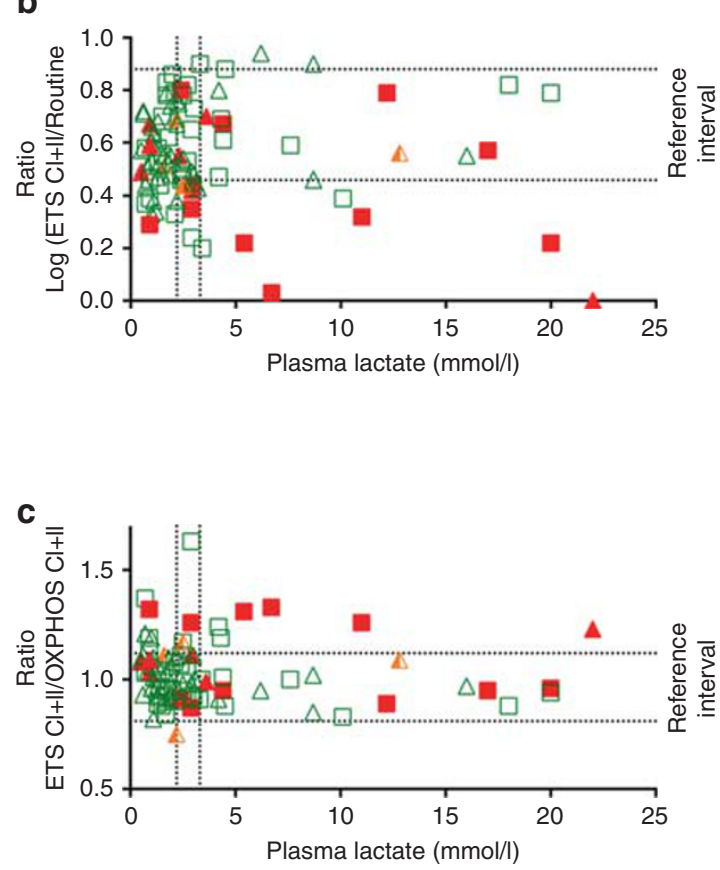
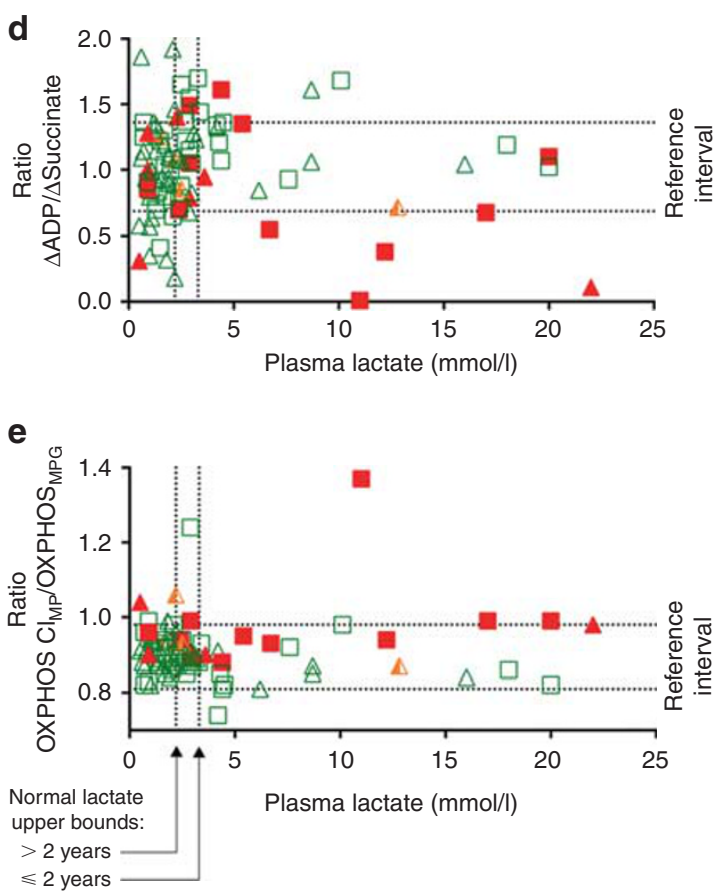

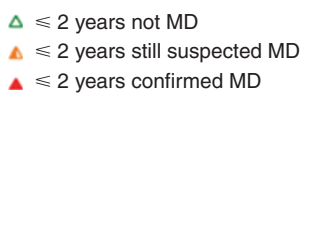

$\square>2$ years not MD

D $>2$ years still suspected MD

- $>2$ years confirmed MD

Figure 2. Plasma lactate and diagnostic ratios. Horizontal dotted lines: respirometry ratio reference interval. Vertical dotted lines: Plasma lactate upper reference bounds (for patients $<2$ years old: $3.3 \mathrm{mmol} / \mathrm{l} ; \geq 2$ years old: $2.2 \mathrm{mmol} / \mathrm{l}$ ). Red: confirmed MD; yellow: still suspected MD; green: no MD. Squares: $>2$ years old; triangles: $\leq 2$ years old.

clinical recovery), was usually further evaluated with muscle biopsy, genetic testing, or both. The final diagnosis was preceded by discussion among several specialists and was made independently of the experimental platelet model.

Patients were defined as having "still suspected" MD if routine diagnostics could neither confirm nor rule out a diagnosis. Patients where disease was "still suspected" were considered as not having $\mathrm{MD}$ in all calculations of diagnostic accury in platelets, unless specified otherwise.

\section{Platelet preparation}

Depending on age and weight of the patient, 6-12 $\mathrm{ml}$ venous blood was drawn to EDTA vials. Blood samples were analyzed within 3-5 h as described previously $(11,17$.)

\section{High-resolution respirometry}

Mitochondrial respiration was measured with an Oxygraph-2k (Oroboros Instruments, Innsbruck, Austria) following a previously described protocol $(11,17)$.

The platelet pellet was dissolved in a mitochondrial respiration medium (MiR05) containing sucrose $110 \mathrm{mM}$, HEPES $20 \mathrm{mM}$, taurine $20 \mathrm{mM}$, K-lactobionate $60 \mathrm{mM}, \mathrm{MgCl}_{2} 3 \mathrm{mM}, \mathrm{KH}_{2} \mathrm{PO}_{4}$ $10 \mathrm{mM}$, EGTA $0.5 \mathrm{mM}$, bovine serum albumin $1 \mathrm{~g} / \mathrm{l}$, at $\mathrm{pH} 7.1$ (ref. 18). The final cell concentration in the chamber was 19-
$200 \times 10^{6}$ cells per ml. Data were recorded with the DatLab Software 4.3 (Oroboros Instruments, Innsbruck, Austria).

\section{Experimental protocol for permeabilized platelets}

The analytic protocol is described in Figure 3. At the onset, the complexes of the respiratory system are coupled to the process of OXPHOS, phosphorylating ADP to adenosine triphosphate (ATP) as oxygen is consumed. The respiratory state in which the respiratory system is active but artificially uncoupled from OXPHOS is termed ETS (electron transport system). If neither OXPHOS nor artificial uncoupling drives the respiratory system, a certain amount of protons leaking over the inner membrane may still drive the respiratory system to some extent, as the mitochondria pump the protons back to maintain the electrochemical potential over the inner mitochondrial membrane. This state is called LEAK.

First, Routine respiration was established. Subsequently, the detergent digitonin was added to permeabilize the plasma membrane and allow the mitochondria to access exogenous (added) substrates. Malate $(5 \mathrm{mM})$ and pyruvate $(5 \mathrm{mM})$ were added simultaneously (respiratory state DMP). ADP $(1 \mathrm{mM})$ was then added to induce OXPHOS with these substrates (OXPHOS $\mathrm{CI}_{\mathrm{MP}}$ ). Further, addition of glutamate $(5 \mathrm{mM})$ provided additional electrons for complex I (CI), also via NADH (OXPHOS $\mathrm{CI}_{\mathrm{MPG}}$ ). Convergent input of electrons through both CI and complex II (CII) was achieved by the addition of succinate $(10 \mathrm{mM})$, which is oxidized by CII. This 


\section{Mitochondrial diagnostics in platelets}

Table 7. Explorative analyses

\begin{tabular}{|c|c|c|c|c|c|c|c|c|}
\hline Test $(n=113)$ & $\begin{array}{l}\text { Confirmed } \\
\text { MD }(n=18)\end{array}$ & $\begin{array}{l}\text { No confirmed } \\
\text { MD }(n=95)\end{array}$ & $\begin{array}{l}\text { Sensitivity } \\
(95 \% \mathrm{Cl})\end{array}$ & $\begin{array}{l}\text { Specificity } \\
(95 \% \text { Cl) }\end{array}$ & $\begin{array}{c}\text { PPV } \\
(95 \% \mathrm{Cl})\end{array}$ & $\begin{array}{c}\text { NPV } \\
(95 \% \mathrm{Cl})\end{array}$ & $\begin{array}{c}\text { PLR } \\
(95 \% \mathrm{Cl})\end{array}$ & $\begin{array}{c}\text { NLR } \\
(95 \% \mathrm{Cl})\end{array}$ \\
\hline \multicolumn{9}{|l|}{ Scaled down model ${ }^{\mathbf{a}}$} \\
\hline Any test positive (38) & 12 & 26 & $67(41-87)$ & $73(63-81)$ & $32(18-49)$ & $92(83-97)$ & $2.4(1.5-3.9)$ & $0.46(0.24-0.89)$ \\
\hline All tests negative (75) & 6 & 69 & & & & & & \\
\hline \multicolumn{9}{|l|}{ OXPHOS CI+II/LEAK } \\
\hline Positive (21) & 6 & 15 & $33(13-59)$ & $84(75-91)$ & $29(11-52)$ & $87(78-93)$ & $2.1(1.0-4.7)$ & $0.79(0.56-1.1)$ \\
\hline Negative (92) & 12 & 80 & & & & & & \\
\hline \multicolumn{9}{|l|}{ Three best tests $3 / 3^{\mathrm{b}}$} \\
\hline $3 / 3$ positive $(3)$ & 3 & 0 & $17(3.6-41)$ & $100(96-100)$ & $100(29-100)$ & $86(79-92)$ & - & $0.83(0.68-1.0)$ \\
\hline Any test negative (110) & 15 & 95 & & & & & & \\
\hline \multicolumn{9}{|l|}{ Test combined with plasma lactate ${ }^{c}$} \\
\hline \multicolumn{9}{|l|}{ OXPHOS $\mathrm{Cl}_{\mathrm{MP}} / \mathrm{DMP}$ low } \\
\hline Positive and high lactate (5) & 4 & 1 & $22(6.4-48)$ & $99(94-100)$ & 80 (28-99) & 87 (79-93) & $21(2.5-178)$ & $0.79(0.61-1.0)$ \\
\hline Negative or low lactate (90) & 14 & 94 & & & & & & \\
\hline \multicolumn{9}{|l|}{ Log(ETS Cl+II/Routine) low } \\
\hline Positive and high lactate (14) & 6 & 8 & $33(13-59)$ & $92(84-96)$ & $43(18-71)$ & $88(80-94)$ & $4.0(1.6-10)$ & $0.73(0.52-1.0)$ \\
\hline Negative or low lactate (99) & 12 & 87 & & & & & & \\
\hline \multicolumn{9}{|l|}{$\triangle A D P / \triangle$ Succinate low } \\
\hline Positive and high lactate (9) & 5 & 4 & $28(9.7-53)$ & $96(90-99)$ & $56(21-86)$ & $88(80-93)$ & $6.6(2.0-22)$ & $0.75(0.56--1.0)$ \\
\hline Negative or low lactate (104) & 13 & 91 & & & & & & \\
\hline \multicolumn{9}{|c|}{$\begin{array}{l}\text { Abbreviations: ADP, adenosine diphosphate; } 95 \% \mathrm{Cl}, 95 \% \text { confidence interval; } \mathrm{Cl}+\mathrm{Il} \text {, complex I and II; ETS, electron transport system; DMP, digitonin, malate and pyruvate; MD, } \\
\text { mitochondrial disease; MP, malate and pyruvate; MPG, malate, pyruvate and glutamate; OXPHOS, oxidative phosphorylation; PLR, positive likelihood ratio; NLR, negative like- } \\
\text { lihood ratio; PPV, positive predictive value; NPV, negative predictive value. } \\
\text { aTwo most sensitive tests: Log(ETS Cl+II/Routine) low and } \triangle \mathrm{ADP} / \triangle S \text { Succinate low. } \\
{ }^{\mathrm{b} O X P H O S C l M P} \text { /DMP low and Log(ETS Cl+II/Routine) low and } \triangle \mathrm{ADP} / \triangle \text { Succinate low. }\end{array}$} \\
\hline
\end{tabular}

achieves maximum OXPHOS capacity through CI and CII (OXPHOS CI+II).

Next, proton leak over the mitochondrial membrane was measured by adding the ATP synthase inhibitor oligomycin $(1 \mu \mathrm{g} /$ $\mathrm{ml}$ ), blocking OXPHOS (LEAK CI+II).

This was followed by titration of the uncoupler protonophore carbonyl cyanide 4-(trifluoromethoxy) phenylhydrazone creating a chemically induced leak of protons over the inner mitochondrial membrane, thereby stimulating the ETS to maintain the chemiosmotic proton gradient (ETS CI+CII). Subsequently, by adding CI inhibitor rotenone, the CII-dependent uncoupled respiration was measured (ETS CII).

To adjust for nonmitochondrial oxygen consumption by the cells, the complex III (CIII) inhibitor antimycin-A was added and this value was subtracted from each of the other parameters.

Finally, tetramethylphenylenediamine $(0.5 \mathrm{mM})$ was added, driving complex IV (CIV) activity through the reduction of cytochrome c. To control oxygen consumed through the autoxidation of tetramethylphenylenediamine, CIV is inhibited by azide $(10 \mathrm{mM})$ and the remaining respiration is subtracted from the former value (CIV activity).

From the measured parameters we constructed five ratios to cover different aspects of mitochondrial dysfunction. We used ratios of respirometry measurements, as opposed to absolute values, thus circumventing the need to adjust for mitochondrial content in the sample. This keeps the protocol simple, rapid, and more compatible with routine clinical use.

A low OXPHOS $\mathrm{CI}_{\mathrm{MP}} / \mathrm{DMP}$ ratio (in the absence of other findings indicating CII-V dysfunction) was assumed to reflect dysfunction in $\mathrm{CI}$ or upstream (of $\mathrm{CI}$ ) processes, such as pyruvate dehydrogenase deficiency, as only CI substrates are present in this state $(13,16)$. A low ETS CI+CII/Routine ratio was assumed to reflect general dysfunction for all complexes except $\mathrm{CV}$ and a reduced reserve capacity of the respiratory system. The OXPHOS CI+II/ETS CI+II was assumed to reflect $\mathrm{CV}$ dysfunction as respiration in the numerator but not in the denominator is limited by CV capacity. The $\Delta \mathrm{ADP} / \Delta$ Succinate ratio was defined to reflect either CI or CII dysfunction. A high response to ADP (in the presence of CI substrates) in comparison with the sequential response to succinate would indicate CII dysfunction and raise the ratio. The opposite would imply CI dysfunction. Finally, we assumed that a low OXPHOS $\mathrm{CI}_{\mathrm{MP}} / \mathrm{OXPHOS} \mathrm{CI}_{\mathrm{MPG}}$ ratio would indicate $\mathrm{PDH}$ deficiency. Transaminases in the malate-aspartate shuttle convert glutamate and oxaloacetate to $\alpha$-ketoglutarate and aspartate, replenishing the tricarboxylic acid cycle downstream of $\mathrm{PDH}$. Increased oxygen consumption with the addition of glutamate could thus indicate a limitation to mitochondrial respiration by PDH (19). 


\section{Articles | Westerlund et al.}

Table 8. Explorative model with stricter true-positive criteria

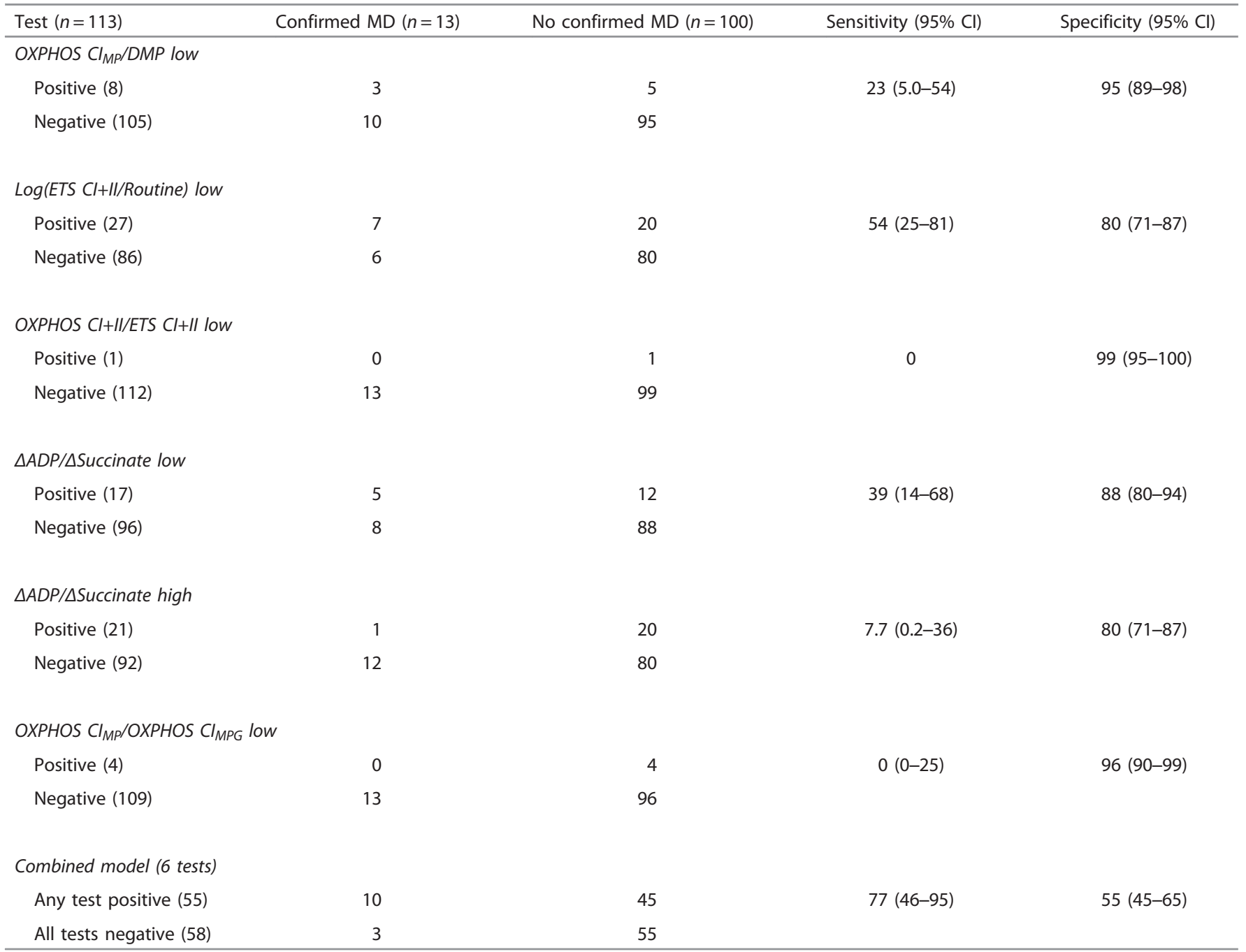

Abbreviations: ADP, adenosine diphosphate; $\mathrm{Cl}+\mathrm{Il}$, complex I and II; ETS, electron transport system; DMP, digitonin, malate and pyruvate; MD, mitochondrial disease; MP, malate and pyruvate; MPG, malate, pyruvate and glutamate; OXPHOS, oxidative phosphorylation.

Disease prevalence in the study population was $12 \%$ with stricter criteria for true positive (only cases confirmed by molecular testing).

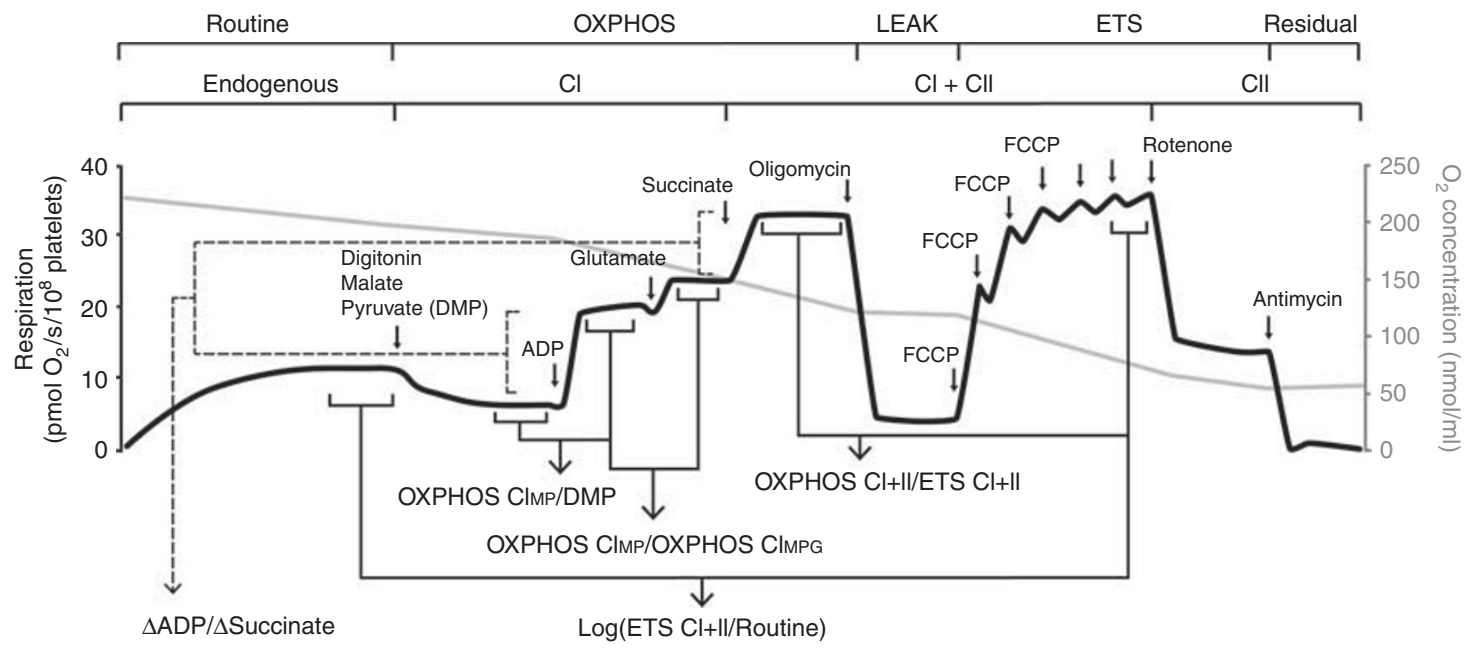

Figure 3. Platelet respirometry protocol. This is an illustration of the main part of the experimental protocol for platelets. The gray curve represents oxygen concentration over time (during around $1 \mathrm{~h}$ ). The black curve represents rate of change in oxygen concentration (respiration). Small arrows mark the addition of substrates, uncouplers, and inhibitors. The diagram below the curve illustrates which respiratory states are compared in each diagnostic ratio for four of the five ratios $\triangle \mathrm{ADP} / \triangle$ Succinate (not shown) compares the change in respiration after addition of $A D P$ with the change after addition of succinate. 


\section{Statistical methods}

Respiratory parameters from a control group of 25 pediatric patients were used to establish reference intervals for the respiratory ratios.

The method for establishing reference intervals was adapted from the Clinical and Laboratory Standards Institute (CLSI) guidelines (20). Outliers were detected with Tukey's outlier labeling rule and two ratios had one outlier each removed (21).

The five chosen ratios were tested for normal distribution with D'Agostinos test for skewness and the Anscombe-Glynn test of kurtosis. All were found to have normal distribution except ETS CI +II/Routine. Logarithmic transformation (base 10) of that ratio produced normal distribution and was used. The reference interval for each ratio was defined as the mean \pm 1.96 standard deviations.

With one-sided hypotheses for four ratios and a two-sided hypothesis for one, ratios were treated as six separate (but not independent) tests with binary outcomes. Diagnostic evaluation was performed for each of the tests separately and for a combined model where positive test result was defined as a positive result in one or more out of the six tests. The relation between test ratios and lactate value was examined with scatter plots.

Diagnostic accuracy was presented as sensitivity, specificity, positive and negative predictive value, and PLR and NLR. Likelihood ratios describe how much information a given test result adds compared with pretest knowledge (22). High PLR indicates that the probability of disease rises after testing positive. A low NLR means a negative result lowers probability of disease. These ratios are independent of disease prevalence.

Statistical analyses were mainly performed with SPSS (IBM SPSS Statistics Software, version 23, IBM Corp., Armonk, NY) and GraphPad PRISM (GraphPad Software, version 6.0d, GraphPad Software, Inc., La Jolla, CA). Tests of normality were performed using Free Statistics Software (Wessa, P. 2015, Office for Research Development and Education, version 1.1.23-r7, URL http://www. wessa.net/) and confidence intervals for the diagnostic evaluation results were calculated with MedCalc (online version 15.11.4, MedCalc Software, Ostend, Belgium). Statistical figures were constructed with GraphPad PRISM.

\section{ACKNOWLEDGMENTS}

We thank Albana Shahini for technical support, Marie Palmquist and AnnCathrine Berg for patient identification and recruitment, and Michael Karlsson, Sarah Piel, and Imen Chamkha for constructive input. We thank Erich Gnaiger for participating in protocol design for the Oroboros $02 \mathrm{k}$ Oxygraph.

\section{STATEMENT OF FINANCIAL SUPPORT}

This work was supported by the Swedish Research Council (Dr Elmér: 2011-3470 and Dr Fellman: 2011-3877), The Crafoord Foundation, Linnéa and Josef Carlsson's Foundation, Swedish government project and salary funding for clinically oriented medical research (ALF Grants), Skåne University Hospital funds, and regional research and development grants (Southern healthcare region, Sweden).

Disclosure: Drs Ehinger, Hansson, and Elmér and Åsander Frostner have equity interests in, and/or have received salary support from NeuroVive Pharmaceutical $A B$, a public company developing pharmaceuticals in the field of mitochondrial medicine. The other authors declare no financial or commercial conflict of interest.

\section{REFERENCES}

1. McFarland R, Taylor RW, Turnbull DM. A neurological perspective on mitochondrial disease. Lancet Neurol 2010;9:829-40.

2. Parikh S, Goldstein A, Koenig MK, et al. Diagnosis and management of mitochondrial disease: a consensus statement from the Mitochondrial Medicine Society. Genet Med 2015;17:689-701.
3. Bernier FP, Boneh A, Dennett X, Chow CW, Cleary MA, Thorburn DR. Diagnostic criteria for respiratory chain disorders in adults and children. Neurology 2002;59:1406-11.

4. Wolf NI, Smeitink JA. Mitochondrial disorders: a proposal for consensus diagnostic criteria in infants and children. Neurology 2002;59:1402-5.

5. Haas RH, Parikh S, Falk MJ, et al. Mitochondrial disease: a practical approach for primary care physicians. Pediatrics 2007;120:1326-33.

6. Yamada K, Toribe Y, Yanagihara K, Mano T, Akagi M, Suzuki Y. Diagnostic accuracy of blood and CSF lactate in identifying children with mitochondrial diseases affecting the central nervous system. Brain Dev 2012;34:92-7.

7. Haas RH, Parikh S, Falk MJ, et al. The in-depth evaluation of suspected mitochondrial disease. Mol Genet Metab 2008;94:16-37.

8. Tulinius MH, Holme E, Kristiansson B, Larsson NG, Oldfors A. Mitochondrial encephalomyopathies in childhood. I. Biochemical and morphologic investigations. J Pediatr 1991;119:242-50.

9. Dinopoulos A, Smeitink J, ter Laak H. Unusual features of mitochondrial degeneration in skeletal muscle of patients with nuclear complex I mutation. Acta Neuropathol 2005;110:199-202.

10. Mancuso M, Calsolaro V, Orsucci D, et al. Mitochondria, cognitive impairment, and Alzheimer's disease. Int J Alzheimers Dis 2009: 2009.

11. Sjovall F, Morota S, Hansson MJ, Friberg H, Gnaiger E, Elmer E. Temporal increase of platelet mitochondrial respiration is negatively associated with clinical outcome in patients with sepsis. Crit Care 2010;14:R214.

12. Ehinger JK, Morota S, Hansson MJ, Paul G, Elmer E. Mitochondrial dysfunction in blood cells from amyotrophic lateral sclerosis patients. J Neurol 2015;262:1493-503.

13. Kunz D, Luley C, Fritz S, et al. Oxygraphic evaluation of mitochondrial function in digitonin-permeabilized mononuclear cells and cultured skin fibroblasts of patients with chronic progressive external ophthalmoplegia. Biochem Mol Med 1995;54:105-11.

14. Artuch R, Colome C, Playan A, et al. Oxygen consumption measurement in lymphocytes for the diagnosis of pediatric patients with oxidative phosphorylation diseases. Clin Biochem 2000;33:481-5.

15. Pecina P, Gnaiger E, Zeman J, Pronicka E, Houstek J. Decreased affinity for oxygen of cytochrome- $c$ oxidase in Leigh syndrome caused by SURF1 mutations. Am J Physiol Cell Physiol 2004;287:C1384-8.

16. Pecina $\mathrm{P}$, Houštková $\mathrm{H}$, Mráček $\mathrm{T}$, et al. Noninvasive diagnostics of mitochondrial disorders in isolated lymphocytes with high resolution respirometry. BBA Clin 2014;2:62-71.

17. Sjovall F, Ehinger JK, Marelsson SE, et al. Mitochondrial respiration in human viable platelets-methodology and influence of gender, age and storage. Mitochondrion 2013;13:7-14.

18. Gnaiger E, Kuznetsov AV, Schneeberger S, et al. Mitochondria in the coldIn:Heldmaier G, Klingenspor Meds. Life in the Cold. Heidelberg, Berlin, Germany and New York: Springer, 2000: 431-42.

19. Ehinger JK, Morota S, Hansson MJ, Paul G, Elmér E. Mitochondrial respiratory function in peripheral blood cells from Huntington's disease patients. Mov Disord Clin Pract 2016;3:472-82.

20. Clinical and Laboratory Standards Institute (CLSI). Defining, Establishing, and Verifying Reference Intervals in the Clinical Laboratory: Approved Guideline3rd ednCLSI Document C28-A3 Wayne, PA: Clinical and Laboratory Standards Institute, 2008.

21. Hoaglin DC, Iglewicz B. Fine-tuning some resistant rules for outlier labeling. J Am Stat Assoc 1987;82:1147-9.

22. McGee S. Simplifying likelihood ratios. J Gen Intern Med 2002;17:646-9.

23. Lieber DS, Calvo SE, Shanahan K, et al. Targeted exome sequencing of suspected mitochondrial disorders. Neurology 2013;80:1762-70.

24. Hutchesson A, Preece MA, Gray G, Green A. Measurement of lactate in cerebrospinal fluid in investigation of inherited metabolic disease. Clin Chem 1997;43:158-61.

25. Chow SL, Rooney ZJ, Cleary MA, Clayton PT, Leonard JV. The significance of elevated CSF lactate. Arch Dis Child 2005;90:1188-9.

26. Davison JE, Rahman S. Recognition, investigation and management of mitochondrial disease. Arch Dis Child 2017 (doi:10.1136/archdischild2016-311370). 